\title{
OS GEÓGRAFOS FRENTE ÀS DINÂMICAS SÓCIO-AMBIENTAIS NO BRASIL
}

\author{
Roberto Verdum
}

\begin{abstract}
Resumo: Para identificar o olhar dos geógrafos frente às transformações no país e suas implicações ambientais trata-se aqui inicialmente da base conceitual utilizada por esses para abordar a relação sociedade-natureza, em seguida, de como os geógrafos abordam esta relação e, finalmente, dos destaques dados por eles na pesquisa relacionada à degradação ambiental, que é resultado concreto das opções adotadas no modelo de desenvolvimento do país.
\end{abstract}

Palavras-chave: Brasil; Geografia; Questão ambiental; Degradação ambiental; Paisagem.

\section{Construção dos geógrafos frente a natureza e a sociedade}

A base conceitual que os geógrafos operam para tratar da relação sociedade-natureza tem se alterado no transcorrer do tempo e com 0 avanço da produção científica. Inicialmente, pode-se considerar que a preocupação dos geógrafos era a de tratar a relação homem-natureza. Esta perspectiva de análise diferenciava a Geografia de outras áreas do conhecimento, de um lado aquelas que analisavam as dinâmicas da natureza e, de outro lado as que se preocupavam com as dinâmicas sociais.

No entanto, nesta abordagem da Geografia, baseada nos pressupostos de Descartes, era fundamental diferenciar o homem da natureza. A natureza era considerada como externa ao homem, analisada como sendo o conjunto dos elementos formadores da Terra (fogo, água, solo, ar). Por outro lado, o homem era visto como um ser biológico na relação com a natureza, podendo-se considerar como sendo uma forma de naturalização do homem (GONÇALVES, 2001). Assim, os geógrafos tinham dificuldades em construir um método que propunha analisar a unidade sociedade-natureza.

Posteriormente, os geógrafos ao se aproximarem das abordagens desenvolvidas pelas ciências sociais (Antropologia, Ciência Política, Economia e a Sociologia) começaram a elaborar noções que enfatizam as relações sociais. Associando-se então a identidade social de um determinado grupo com os conceitos de lugar, território e região. Assim, a Geografia passa a ser aquela ciência que não necessariamente estudaria a relação entre os homens, mas sim, os lugares, como referenciaria Vidal de la Blache.

Essa aproximação com os referenciais construídos pelas ciências sociais criou a possibilidade para os geógrafos de alterarem as bases para compreender a relação entre os homens $\mathrm{e}$ a natureza. 0 conceito de espaço geográfico é elaborado como sendo 0 resultado das maneiras de como os homens organizam sua vida e suas formas de produção. Nesta perspectiva, a natureza passa a ser vista como recurso à produção, o que aponta para uma limitação quanto à possibilidade analítica em relação às dinâmicas da natureza.

Assim, analisando os referenciais teóricos-metodológicos e as práticas de pesquisa dos geógrafos, nesse momento da produção científica, frente à relação sociedade-natureza, observase duas abordagens diferentes, uma que considera a natureza como recurso e outra que considera a dinâmica da natureza como suporte da vida humana, com suas dinâmicas próprias (SANTOS, 1998). É na busca da ruptura desta dicotomia que os geógrafos experimentaram criar novos suportes para estudar a relação sociedade-natureza (CASSETI, 1991).

Neste sentido, algumas rupturas epistemológicas podem ser destacadas como referências para 0 desenvolvimento das práticas científicas dos geógrafos:

a) romper com a compreensão que considera 0 homem exclusivamente como um ser natural $\mathrm{e}$;

b) reconhecer que a cultura humana é cada vez mais vasta $\mathrm{e}$ diversificada, sendo carregada de elementos técnicos que permitem a esse homem modificar e, até mesmo, (re)criar a natureza.

A partir dessas rupturas é possível reconhecer novas práticas do fazer geográfico que abordam as intervenções humanas na natureza nas diversas formas de organização social, (ROSS, 1990; MENDONÇA, 2001). Aos geógrafos não seria mais

1 Universidade Federal do Rio Grande do Sul, Professor Doutor do Departamento de Geografia-Instituto de Geociências, verdum@ufrgs.br 
suficiente abordar, por exemplo, os impactos ambientais meramente como impactos antrópicos, situados numa esfera genérica de análise em relação aos detentores do poder e dos modos de produção na(s) sociedade(s) humana(s). Para desenvolver seus estudos na busca dessa relação sociedadenatureza são diversas as categorias de análise utilizadas pelos geógrafos, entre elas pode-se citar: meio ambiente, paisagem, ecossistema e recurso natural.

Atualmente, na perspectiva de estudar as dinâmicas que se estabelecem na relação sociedade-natureza os geógrafos são confrontados a certos desafios, tais como:

- identificar que a degradação ambiental no meio rural e urbano traz a marca de nossas opções no passado, tanto do desconhecimento que se tinha das dinâmicas da natureza e dos desdobramentos das intervenções sociais nessas dinâmicas, como no que se refere ao cinismo e à ganância produtiva;

- reconhecer o grau de estabilidade e o potencial geoecológico dos ambientes, isto é, os limites de tolerância que, quando ultrapassados alteram sua dinâmica, tornando a degradação gerada irreversível em 25 anos, ao se considerar o período de surgimento de uma nova geração;

- planejar o espaço de tal forma que os ecossistemas artificiais produzidos pelas diversas formas de modernização da agricultura, e que fornecem os recursos para a sociedade, possam funcionar sem degradações ambientais, permitindo assim a continuidade do desenvolvimento dos processos produtivos.

\section{A trajetória dos geógrafos no reconhecimento das degradações ambientais}

Pode-se afirmar que o reconhecimento, pelos geógrafos, dos desastres ambientais ocorre no pós-guerra e durante a intensificação do processo de colonização européia na África, quando foram adotadas práticas agrícolas de matrizes culturais produtivas dos países colonizadores. Já na década de 1940, por exemplo, a desertificação era reconhecida como um processo de degradação das terras devido às práticas agrícolas que guardavam na sua essência as práticas empregadas em terras européias com características completamente distintas das utilizadas no continente africano (SUERTEGARAY et al., 2001).

Posteriormente a este período, geógrafos franceses como George Bertrand, Jean Tricart, André Cailleux, Jean Dresch e Pierre Gourou passaram a reconhecer, a partir de uma abordagem sistêmica, as mais variadas degradações decorrentes da continuidade da adoção de modelos de produção agrícola incompatíveis com as dinâmicas da natureza local. Dinâmicas estas em grande parte desconhecidas pelos planejadores, que desconsideravam tanto o grau de estabilidade e o potencial geoecológico dos ecossistemas como o limite de resiliência (resistência à mudança) de um determinado ecossistema (TRICART, 1994).

No Brasil, geógrafos como Léo Waibel, Emanuel de Martonne, Orlando Valverde, Aziz Ab'Saber e Manoel Correa de Andrade podem ser considerados os precursores dos estudos das transformações do espaço geográfico pelas diferentes modernizações pela qual passou a agricultura. Através da abordagem considerada como sendo a da paisagem cultural, esses geógrafos são, na sua maioria, testemunhas vivas das opções de desenvolvimento rural brasileiro e das degradações ambientais, do Rio Grande do Sul à Amazônia. Eles apontam, até hoje, os malefícios das políticas agrícolas adotadas por nós brasileiros e as degradações que marginalizam as áreas de potencial produtivo, assim como as que se caracterizam como identidade única no universo dos ecossistemas tropicais, (PNMA, 1996; BECKER et al., 2002).

Além disso, sinalizam a ignorância e 0 nosso desconhecimento do potencial geo-ecológico desses ecossistemas e dos seus limites. Desta forma, há a necessidade de se intensificar o debate sobre os modelos produtivos, a preservação e a conservação ambiental (VERDUM e MEDEIROS, 2002). Deve-se considerar a natureza e o patrimônio cultural, assim como a criação/adaptação de modelos de produção agrícola no mundo tropical, lembrando que o patrimônio cultural se insere numa história de ocupação e conformação do território brasileiro.

\section{A paisagem como categoria de análise das transformações sócio-ambientais}

A proposta de caracterizar as transformações sócioambientais pela análise espacial e paisagem pressupõe definir as diferenciações entre as unidades de paisagem (UPs), essencialmente referenciadas em quatro critérios: a forma, a função, a estrutura e a dinâmica, (ROUGERIE e BEROUTCHACHILI, 1991; ROGER, 1995).

A forma é 0 aspecto visível de uma determinada paisagem, sendo que é composta por elementos que podem ser facilmente reconhecidos em campo, assim como pelo uso dos produtos do sensoriamento remoto (fotos aéreas e imagens de satélite): o morfológico, a presença de água, a cobertura vegetal e a ocupação das terras. Cada forma possui diferenças, tanto do ponto de vista de suas dinâmicas como, também, da possibilidade de 
apropriação e uso social, isto é, a sua função. (SILVEIRA, 2005).

Sendo assim, a função pode ser compreendida pelas atividades que, de certa maneira, foram ou estão sendo desenvolvidas e que estão materializadas nas formas criadas socialmente (espaço construído, atividades agrícolas, atividades mineradoras...) e, que também são reconhecidas em campo e pelos produtos do sensoriamento remoto pelas diferenciações que apresentam em relação aos aspectos das unidades da paisagem, onde não ocorrem as diversas formas criadas socialmente (WINTER, 2004).

A estrutura é outro critério que não pode ser dissociado da forma e da função, sendo esta reconhecida como a que revela os valores e as funções dos diversos objetos que foram concebidos em determinado momento histórico. Desse modo, a estrutura revela a natureza social e econômica dos espaços construídos e que, de certa maneira, interfere na dinâmica da paisagem anterior às intervenções sociais.

A dinâmica é a ação contínua que se desenvolve gerando diferenças entre as UPs, no tempo, na sua continuidade e na sua mudança. 0 tempo (geológico e histórico) revela o movimento do passado ao presente, e este em direção ao futuro. Neste caso, as dinâmicas de cada UPs revelam para a sociedade significados que podem ser reconhecidos pelas formas e podem ser pensados em termos de intervenções que já foram realizadas e que serão propostas: o zoneamento, a efetivação e os usos (SANCHIS, 2005). Neste sentido, é fundamental o reconhecimento das diversas dinâmicas em cada uma das UPs, assim como de suas interconexões.

Sendo estabelecidos esses critérios para diferenciar as UPS, cabe destacar que é fundamental reconhecer que a utilização da categoria paisagem na perspectiva conservacionista $e$ preservacionista gera e gerará uma marca que altera as relações que se estabelecem na ocupação das terras no seu entorno (VIEIRA, 2004). Assim, há a necessidade de a UP seja reconhecida socialmente por suas formas, funções, estruturas e dinâmicas, que seja englobada como parte importante da dimensão histórica e cultural do lugar e da área de entorno (HEIDRICH et al., 2005).

\section{Considerações finais}

Como propostas para o presente e 0 futuro é fundamental reafirmar 0 debate sobre 0 combate à fome e às doenças associadas a um projeto de desenvolvimento que considere como essencial as potencialidades produtivas, a preservação e a conservação ambiental. É importante afirmar a necessidade de sistematizar, na escala do território nacional e regional, 0 conhecimento do potencial produtivo e de seus limites para se definir políticas públicas e privadas relativas ao desenvolvimento rural. Considera-se relevante também definir esses potenciais e os limites da produção associados à análise das capacidades tecnológicas, técnicas e de métodos atuais, que se modificam ao longo do tempo.

Analisando a produção geográfica atual, percebe-se a elaboração de estudos que consideram diferentes abordagens construídas pelos próprios geógrafos, no que se refere à relação natureza-sociedade, tais como: paisagem, domínios morfoclimáticos, geossistemas, ecodinâmica, etc... 0 fundamental nestes estudos é 0 fato de contribuírem gradativamente para se reconhecer, a partir dos elementos herdados, as diferentes formas de medidas de proteção ambiental que podem ser empregadas.

Acredita-se que essa parcela de contribuição gerada pelos geógrafos deva servir como referencial nos questionamentos e nas decisões em relação à adoção de modelos de modernização, tanto em relação ao meio rural como urbano, principalmente naquelas que levam em consideração exclusivamente os mecanismos econômicos e políticos, em detrimento das dinâmicas ambientais. Neste sentido, deve-se levar em conta que ao desconhecer a importância dessas dinâmicas, não só estaremos gerando fontes de degradação na natureza, mas certamente, nos fatores socioeconômicos que sustentam as relações humanas. 
VERDUM, R. (2005). Les Recherches Geographiques au contexte sociaux-ambientalle. Revista do Departamento de Geografia, n. 16, p. 9194.

Resumé: Pour identifier le regard des géographes vis-à-vis les transformations dans le pays et ses rapports avec les dégradations environnementaux, on propose récupérer la base conceptuelle élaborée pour analyser le rapport société-nature. Ensuite, on expose comment les géographes développent des méthodes pour travailler ce rapport et, finalement, les remarques de la dégradation environnementale faites pour les géographes comme étant le résultat concret des options adoptées dans le modèle de développement du pays.

Mots-clefs: Brésil; Géographie; Question environnementale; Dégradation environnementale; Paysage.

Recebido em 7 de setembro de 2005, aceito em 2 de outubro de 2005.

\section{Referências}

BECKER, B.K. e outros (org.) (2002). Geografia e meio ambiente no Brasil. São Paulo, Hucitec. 397p.

CASSETI, W. (1991) Ambiente e apropriação do relevo. São Paulo, Contexto. 147p.

GONÇALVES, C.W.P. (2001). Geo-grafías. México, Syglo veintiuno editors.

HEIDRICH, A.L. e outros (2005) Diagnóstico socioeconômico e ambiental da Unidade de Conservação do Parque Estadual de Itapeva. Relatório Técnico. Porto Alegre: Departamento de Geografia//G/UFRGS.

MENDONÇA, F. de A. (2001) Geografia e meio ambiente. São Paulo, Contexto. 80p.

ROGER, Alain (org.). (1995) La théorie du paysage en France. Seyssel, Éditions Champ Vallon. 463p.

PROGRAMA NACIONAL DE MEIO AMBIENTE (PNMA) (1996) Os ecossistemas brasileiros e os principais macrovetores de desenvolvimento. Brasília: Ministério do Meio Ambiente, dos Recursos Hídricos e da Amazônia Legal.

ROSS, J. (1990) Geomorfologia - ambiente e planejamento. São Paulo, Contexto. 85p.

ROUGERIE, G. e BEROUTCHACHILI, N. (1991). Géosystèmes et paysages: bilan et méthodes. Paris, Armand Colin Éditeur. 302p.

SANCHIS, M.A.Z. (2005) $A$ instalação do bosque de pinus e suas conseqüências nas dunas do Pontal de Tapes - RS.
Dissertação de Mestrado. Porto Alegre: Programa de Pósgraduação em Geografia/IG/UFRGS.

SANTOS, M. (1998) Técnica Espaço Tempo - globalização e meio técnico-científico informacional. São Paulo, Hucitec. 190p.

SILVEIRA, C.T. (2005) Da Paisagem do Vale Três Forquilhas. Trabalho de Graduação. Porto Alegre: Departamento de Geografia/IG/UFRGS.

SUERTEGARAY, D.M.A.; GUASSELLI, L.; VERDUM, R. (2001) Atlas da arenização - sudoeste do Rio Grande do Sul. Porto Alegre: Centro Estadual de Sensoriamento e Meteorologia do Estado do Rio Grande do Sul, Secretaria da Coordenação e Planejamento do Estado do Rio Grande do Sul e Secretaria da Ciência e Tecnologia do Estado do Rio Grande do Sul.

VERDUM, R.; MEDEIROS, R.M.V. (2002) RIMA - Relatório de Impacto Ambiental: legislação, elaboração e resultados. Porto Alegre, /Editora da Universidade/UFRGS. 210p.

VIEIRA, L.M. dos S. (2004) Paisagem da Reserva Biológica Estadual Mata Paludosa como um recurso de educação ambiental. Trabalho de Graduação. Porto Alegre: Departamento de Geografia//G/UFRGS.

WINTER, J.E. (2004) Caracterização da mineralização de ametista da região do Alto Uruguai: impactos ambientais e avaliação dos rejeitos. Trabalho de Graduação. Porto Alegre: Curso de Geologia/IG/UFRGS.

TRICART, J. (1994) Écogeographie des espaces ruraux. Paris: Editions Nathan. 